\title{
A prospective study of predictors of metabolic syndrome in women with polycystic ovary syndrome
}

\author{
Jubie Gupta*, Santosh Minhas, Monika Jindal
}

Department of Obstetrics and Gynaecology, Maharishi Markandeshwar Medical College and Hospital, Solan, Himachal Pradesh, India

Received: 29 January 2022

Revised: 12 February 2022

Accepted: 14 February 2022

\section{*Correspondence:}

Dr. Jubie Gupta,

E-mail: jubiegupta@gmail.com

Copyright: (C) the author(s), publisher and licensee Medip Academy. This is an open-access article distributed under the terms of the Creative Commons Attribution Non-Commercial License, which permits unrestricted non-commercial use, distribution, and reproduction in any medium, provided the original work is properly cited.

\begin{abstract}
Background: Polycystic ovary syndrome (PCOS) is a well-known gynecological hormonal imbalance. The consequences of PCOS pose a substantial risk for the development of metabolic and cardiovascular abnormalities similar to those that make up metabolic syndrome (MBS). Therefore, there was a need to identify predictors for MBS in PCOS subjects and study their strength of association.

Methods: A prospective observational study was carried on 100 PCOS subjects for having features of MBS. MBS was diagnosed by National cholesterol education program's adult treatment panel III 2001 criteria. Student's independent t test, Chi square test and Fisher's exact test were used for statistical analysis.

Results: The present study estimated the prevalence of MBS in women with PCOS to be $31 \%$. MBS in PCOS was more prevalent in non-vegetarians $(51.6 \%)$. The individual components of MBS criterion had a statistically significant $p$ value $(\mathrm{p}=0.001$ to 0.008$)$ for development of PCOS. Raised levels of triglycerides, fasting blood sugars and fasting insulin tests were related directly to MBS development, with statistically significant $p$ values $(<0.001,<0.001$ and 0.005$)$, respectively.

Conclusions: Women with PCOS have a high prevalence of MBS and its individual components, particularly raised laboratory values of triglycerides, fasting blood sugars and fasting insulin. MBS in PCOS women is associated with advancing age and obesity.
\end{abstract}

Keywords: Metabolic syndrome, Obesity, Polycystic ovary syndrome

\section{INTRODUCTION}

In 1935, Stein and Leventhal first described the PCOS. In modern literature it is famously known as Stein-Leventhal syndrome. ${ }^{1}$ PCOS, a well-known hormonal disorder commonly found in women of reproductive age group, which often results in formation of cysts in the ovaries, making the ovaries bulky. There is no doubt that obstetricians and gynecologists face a great deal of challenge to cope with the complications associated with PCOS.
The prevalence of PCOS among women with reproductive age was 6-15\%. ${ }^{2}$ Women with PCOS may have irregular and prolonged periods. These irregularities generally arise because of abnormally high levels of male hormones called androgens, however, the precise cause of PCOS is still unknown but can be attributed to multiple factors like genetic influences, excess insulin and low-grade inflammation. Usually, the clinical characterization of PCOS varies widely. Chronic anovulation and hyperandrogenism along with altering manifestations like oligomenorrhea, infertility, hirsutism and acne are some classical features. ${ }^{3}$ 
After a successful consensus on the preposition of criteria for PCOS, revised Rotterdam criteria were developed, according to which at least two of the following three criteria are required for the diagnosis of PCOS: oligo- or anovulation, clinical and/or biochemical signs of hyperandrogenism and polycystic ovaries; after excluding other etiologies like congenital adrenal hyperplasia, Cushing's syndrome androgen-secreting tumours. ${ }^{4}$

Metabolic syndrome is a group of metabolic derangements including abdominal obesity, insulin resistance, hypertension, dyslipidaemia and impaired glucose metabolism posing an increased risk of coronary heart disease and type 2 diabetes mellitus. There are some studies that reveal a critical link between metabolic syndrome and PCOS. NCEP ATP III (2001), has laid down a standard criteria for diagnosis of metabolic syndrome - the presence of three or more of the following factors are required: blood pressure of $>130 / 85 \mathrm{mmHg}$, waist circumference of $>88 \mathrm{~cm}$, high density lipid levels of $>1.295 \mathrm{mmol} / \mathrm{l}(50 \mathrm{mg} / \mathrm{dl})$, triglyceride level of $>150$ $\mathrm{mg} / \mathrm{dl}$ and fasting plasma glucose level of $>110 \mathrm{mg} / \mathrm{dl} .^{5}$

Research was evident that there was an overlapping of MBS and many of the anthropometric and metabolic abnormalities of PCOS. Both were actually the triggering factors for most of the adult-onset diseases including diabetes mellitus and cardiovascular diseases. So, in order to grasp the clear association between MBS and PCOS, we have studied the prevalence of MBS in women with PCOS, in an attempt to improve the physical and clinical parameters optimally associated with MBS of PCOS diagnosed women.

\section{METHODS}

A hospital-based, prospective observational study was done on 100 PCOS subjects between the age group of 1545 years attending the gynecology outpatient department from March 2019 to August 2021, in Maharishi Markandeshwar medical college and hospital, Solan ( $\mathrm{H}$. P.), after approval from institutional ethical committee in patients having the following inclusion and exclusion criteria.

\section{Inclusion criteria}

Age between 15 to 45 years, all women irrespective of their marital status and parity, history of menstrual abnormalities, presence of hirsutism or acne and ultrasound diagnosis of PCOS were included in the study.

\section{Exclusion criteria}

Pregnant women, lactating women, women on oral contraceptives or taking drugs that affect carbohydrate metabolism, women who are diagnosed to have thyroid disorders, hyperprolactinemia, Cushing's syndrome, congenital adrenal hyperplasia, diabetes mellitus or androgen secreting tumors and women who have not given their consent to be a part of this study were excluded.

After taking informed and written consent, demographic data and thorough history was taken from the patients regarding their age, socio-economic status (modified Kuppuswamy scale), education status, present and past clinical history, menstrual and obstetric history, personal and family history or any other history as deemed necessary. Anthropometric measurements, clinical features and hirsutism scoring (Ferriman Gallway score) were recorded in each patient. The subjects were asked to undergo biochemical investigations: $\mathrm{LH}$ and FSH levels in early follicular phase (day 2 or 3 of spontaneous menstruation), triglycerides, HDL, fasting blood sugar, fasting insulin, serum testosterone, DHEA-S, TSH and PRL.

The recorded data was compiled and entered in a spreadsheet (Microsoft excel) and then exported to data editor of SPSS version 20.0 (SPSS Inc., Chicago, Illinois, USA). Continuous variables were expressed as mean \pm SD and categorical variables were summarized as frequencies and percentages. Graphically the data was presented by bar and pie diagrams. A $p$ value of less than 0.05 was considered statistically significant.

\section{RESULTS}

The most common age of distribution was between 25-35 years of age. Out of 100 subjects studied, subjects belonging to urban area were in majority, 64\%. All the study subjects were educated, out of which $34 \%$ were graduates as described in Table 1. PCOS was observed to be more prevalent $(63 \%)$ in subjects who belonged to affluent classes (upper and upper middle class) (Table 2).

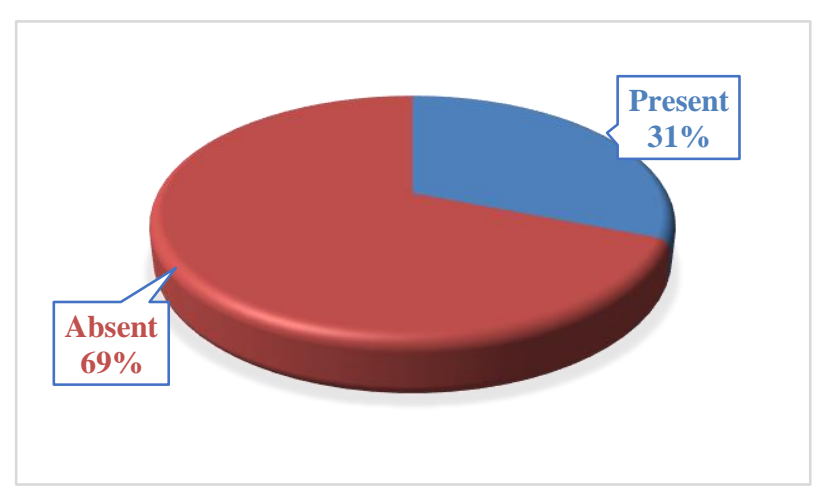

Figure 1: Prevalence of MBS.

MBS was prevalent in $31 \%$ cases in the study (Figure 1). Mean BMI of study subjects was $27.04 \mathrm{~kg} / \mathrm{m}^{2}$. The study subjects were further grouped into lean (BMI $<25 \mathrm{~kg} / \mathrm{m}^{2}$ ) and obese (BMI $>25 \mathrm{~kg} / \mathrm{m}^{2}$ ) PCOS. Among the 100 study subjects, $63 \%$ were obese, out of which 22 had MBS (Table 3). Most PCOS subjects were vegetarians (63\%). However, MBS in PCOS was more prevalent in nonvegetarians $(51.6 \%)$. On studying the individual 
components of MBS criterion, it was observed that all had a statistically significant value in the study subjects (Table 4).

Mean waist circumference was $88.5 \mathrm{~cm}$ in the subjects with MBS and 84.3 in subjects without MBS. Both the values were above the cut-off of $80 \mathrm{~cm}$ meant for South Asian women as described by WHO. The mean waist-hip ratio was 0.92 in the subjects with metabolic syndrome and 0.89 in subjects without metabolic syndrome, which was also above the WHO cut off of 0.85 meant for South Asian women. Further, the mean BMI in the subjects with metabolic syndrome (32.10) falls under WHO obese class I category. For the subjects without MBS, the mean BMI was 28.52 which falls in overweight category according to WHO guidelines. While statistically analyzing these anthropometric measurements-waist circumference $(\mathrm{p} \leq 0.001)$, waist-hip ratio $(\mathrm{p}=0.001)$ and BMI $(\mathrm{p}=0.001)$, all had a highly significant association of MBS in women with PCOS (Table 5).

Table 1: Education $(\mathrm{n}=100)$.

\begin{tabular}{|llll|}
\hline S. No. & Education & Total & Percentage \\
\hline 1. & Illiterate & 0 & 0 \\
\hline & Literate & 100 & 100 \\
\cline { 2 - 5 } & High School & 18 & 18 \\
\multirow{2}{*}{ 2. } & Undergraduate & 19 & 19 \\
& Graduate & 34 & 34 \\
\cline { 2 - 5 } & Postgraduate & 29 & 29 \\
\hline
\end{tabular}

Table 2: Socioeconomic status $(\mathbf{n}=\mathbf{1 0 0})$.

\begin{tabular}{|c|c|c|c|}
\hline S. No. & $\begin{array}{l}\text { Socioeconomic class (modified Kuppuswamy socio-economic status scale } \\
\text { 2021) }\end{array}$ & Total & Percentage \\
\hline 1. & Upper & 29 & 29 \\
\hline 2. & Upper middle & 34 & 34 \\
\hline 3. & Lower middle & 19 & 19 \\
\hline 4. & Upper lower & 18 & 18 \\
\hline 5. & Lower & 0 & 0 \\
\hline
\end{tabular}

Table 3: Lean and obese PCOS.

\begin{tabular}{|llllll|}
\hline S. No. & PCOS $(\mathbf{n}=\mathbf{1 0 0})$ & With MBS $(\mathbf{n}=\mathbf{3 1})$ & Without MBS $(\mathbf{n}=\mathbf{6 9})$ & Total & P value \\
\hline 1. & Lean PCOS & 9 & 28 & 37 & 0.268 \\
\hline 2. & Obese PCOS & 22 & 41 & 63 & \\
\hline
\end{tabular}

Table 4: Individual components of MBS in PCOS ( $n=100)$.

\begin{tabular}{|lllllll|}
\hline \multirow{2}{*}{ S. No. } & Components of MBS & \multicolumn{2}{l}{ With MBS $(\mathbf{n = 3 1})$} & \multicolumn{2}{l|}{ Without MBS (n=69) } & \multirow{2}{*}{ P value } \\
\cline { 3 - 6 } & No. & Percentage & No. & Percentage & \\
\hline 1. & Waist circumference $\geq 88 \mathrm{~cm}$ & 22 & 71.0 & 7 & 10.1 & $<0.001$ \\
\hline 3. & HDL-cholesterol $<50 \mathrm{mg} / \mathrm{dl}$ & 25 & 80.6 & 13 & 18.8 & $<0.001$ \\
\hline 4. & Triglycerides $\geq 150 \mathrm{mg} / \mathrm{dl}$ & 30 & 96.8 & 2 & 2.9 & $<0.001$ \\
\hline 5. & Blood pressure $\geq 130 / 85$ & 8 & 25.8 & 1 & 1.4 & 0.008 \\
\hline
\end{tabular}

Table 5: Anthropometric parameters (n=100).

\begin{tabular}{|lllllll|}
\hline \multirow{2}{*}{ S. No. } & Parameters & \multicolumn{2}{c|}{ With MBS $(\mathbf{n}=\mathbf{3 1})$} & \multicolumn{2}{c|}{ Without MBS $(\mathbf{n = 6 9 )}$} & P value \\
\hline 1. & Waist circumference & Mean & SD & Mean & SD & \\
\hline 2. & Waist-hip ratio & 08.52 & 3.59 & 84.30 & 2.88 & $<0.001$ \\
\hline 3. & BMI & 32.19 & 4.24 & 28.52 & 3.65 & $<0.001$ \\
\hline
\end{tabular}


Table 6: Clinical profile of PCOS with MBS.

\begin{tabular}{|lllllll|}
\hline S. No. & Clinical features & $\begin{array}{l}\text { With MBS }(\mathbf{n}=\mathbf{3 1}) \\
\text { Lean PCOS } \\
(\mathrm{n}=9)\end{array}$ & Lean $\%$ & $\begin{array}{l}\text { Obese PCOS } \\
(\mathrm{n}=22)\end{array}$ & Obese $\%$ & P value \\
\hline 1. & Irregular cycles & 9 & 100 & 21 & 95.5 & 0.516 \\
\hline 2. & Amenorrhea & 2 & 22.2 & 8 & 36.4 & 0.732 \\
\hline $\mathbf{3 .}$ & Acne & 4 & 44.4 & 15 & 68.2 & 0.409 \\
\hline 4. & Voice change & 1 & 11.1 & 7 & 31.8 & 0.457 \\
\hline $\mathbf{5 .}$ & Hirsutism & 3 & 33.3 & 8 & 36.4 & 0.873 \\
\hline 6. & Infertility & 0 & 0 & 2 & 9.1 & 1.000 \\
\hline 7. & Alopecia & 0 & 0 & 2 & 9.1 & 1.000 \\
\hline 8. & Acanthosis nigricans & 0 & 0 & 3 & 13.6 & 0.537 \\
\hline
\end{tabular}

Table 7: Laboratory parameters $(n=100)$.

\begin{tabular}{|c|c|c|c|c|c|c|}
\hline \multirow[t]{2}{*}{ S. No. } & \multirow[t]{2}{*}{ Parameters } & \multicolumn{2}{|c|}{$\begin{array}{l}\text { With MBS } \\
(\mathrm{n}=31)\end{array}$} & \multicolumn{2}{|c|}{$\begin{array}{l}\text { Without MBS } \\
(\mathrm{n}=69)\end{array}$} & \multirow[t]{2}{*}{$P$ value } \\
\hline & & Mean & SD & Mean & SD & \\
\hline 1. & TGL (mg/dl) & 167.2 & 7.80 & 137.4 & 7.47 & $<0.001$ \\
\hline 2. & $\mathrm{HDL}(\mathrm{mg} / \mathrm{dl})$ & 45.71 & 14.83 & 57.08 & 11.12 & $<0.001$ \\
\hline 3. & FBS (mg/dl) & 110.4 & 14.56 & 92.46 & 9.52 & $<0.001$ \\
\hline 4. & Fasting insulin & 3.21 & 1.34 & 2.51 & 1.03 & 0.005 \\
\hline 5. & LH (mg/dl) & 9.67 & 2.14 & 10.95 & 2.94 & 0.029 \\
\hline 6. & FSH (mg/dl) & 5.74 & 1.49 & 6.03 & 1.16 & 0.297 \\
\hline 7. & LH/FSH & 1.75 & 0.406 & 1.83 & 0.362 & 0.345 \\
\hline 8. & TSH (mg/dl) & 2.42 & 0.501 & 2.40 & 0.661 & 0.856 \\
\hline 9. & PRL (ng/ml) & 17.97 & 6.74 & 17.95 & 7.02 & 0.991 \\
\hline 10. & Testosterone (ng/ml) & 27.62 & 10.56 & 24.78 & 7.97 & 0.186 \\
\hline 11. & DHEAS $(\mu \mathrm{g} / \mathrm{ml})$ & 5.01 & 2.71 & 4.99 & 2.94 & 0.976 \\
\hline
\end{tabular}

On studying the clinical profile of subjects with MBS with respect to lean and obese categories, there was no statistical difference in the complaints of the subjects in both categories. Though, obese PCOS subjects with irregular cycles were $95.5 \%$ (21 out of 22 ), followed by acne which were $68.2 \%$ (15 out of 22) (Table 6).

Values of TGL, FBS and fasting insulin were related directly to MBS development in study subjects, which were observed to be statistically significant $(\mathrm{p} \leq 0.001)$, $(\mathrm{p} \leq 0.001)$ and $(\mathrm{p}=0.005)$, respectively. However, HDL values had an inverse relationship with development of Metabolic syndrome $(\mathrm{p}<0.001)$ probably due to protective effect of HDL (Table 7).

\section{DISCUSSION}

The consequences of the PCOS extended beyond the reproductive axis. Women with PCOS were at substantial risk for the development of metabolic and cardiovascular abnormalities similar to those that make up the metabolic syndrome. This finding was not surprising, since both the PCOS and the MBS shared overlapping pathogenic features. We sought to identify factors that served as predictors for the MBS using data from subjects, who have been diagnosed with PCOS.
The mean age of subjects with MBS and without MBS was found to be $28.6 \pm 4.40$ years and $25.3 \pm 2.38$ years, respectively. The mean age values were comparable to Carmina et al and Dey et al studies and had a statistically significant association between MBS and higher age of women with PCOS. ${ }^{6,7}$ In the current study, PCOS was seen more in upper middle socio-economic classes (34\%) followed by upper socioeconomic class (29\%). Indu et al in their study, observed that upper socioeconomic classes (47.5\%) had more cases. This was probably due the unhealthy food habits, more dependence on fast food and sedentary lifestyle leading to obesity and its consequences. $^{8}$

Features of lean PCOS started in adolescence, whereas the metabolic changes were further deteriorated with advanced age leading to obesity. In the 2016 study by Akshaya et al the lean PCOS (44\%) were less than obese PCOS (56\%). ${ }^{9}$ Similarly, in the present study when obese PCOS $(63 \%)$ were compared to lean PCOS $(37 \%)$, obese PCOS were observed to more. Obesity worsened insulin resistance, extent of hyperinsulinemia, severity of ovulatory and menstrual dysfunction and was associated with an increasing prevalence of MBS. While comparing the lean and obese PCOS in the current study, most PCOS subjects with MBS fell under the obese category (70.9\%) 
as compared to lean one $(29.1 \%)$, suggesting that the metabolic features of PCOS were worsened by obesity.

Prevalence of MBS observed in various studies by Indu et al, Ehrmann et al and Mandrelle et al was 37.3\%, 33.4\% and $37.5 \%$, respectively.,10,11 These values were comparable to our study with $31 \%$ prevalence of MBS in women with PCOS. Therefore, PCOS was directly related to MBS and comprised of high-risk population for MBS and its consequences.

BMI in the present study, (with and without MBS groups $32.19 \pm 4.24$ versus $28.52 \pm 3.65)$ was comparable to the other studies of Ehrmann et al $(40.4 \pm 0.7$ versus $33.8 \pm 0.5)$ and Zahiri et al $(32.92 \pm 10.80$ versus $27.37 \pm 10.94)$, suggesting that higher BMI led to obesity, which was linked to development of MBS in PCOS. ${ }^{10,12}$

When waist circumference was compared with other studies, mean value in MBS group $(88.52 \pm 3.59)$ was comparable to the study of Zahiri et al $(97.24 \pm 11.14) .{ }^{12}$ However, in the study of Ehrmann et al $(112.7 \pm 1.5)$ it was higher. ${ }^{10}$ This was probably due to the fact that the latter study was conducted in USA, where obesity was a major health issue. Furthermore, in the group without MBS, the results were comparable to the studies of Ehrmann et al and Zahiri et al suggesting that there were no ethnic or racial differences in this parameter and this probably reflected the increase in the total body fat present in the visceral compartment. ${ }^{10,12}$ Due to increase in the sedentary lifestyle, obesity was becoming a health problem in India as well. On comparing waist/hip ratio in various studies, a raised mean value $(\geq 0.85)$ in the MBS group was observed in both the studies Ehrmann et al and Mandrelle et al,which was comparable to the present study. With the increase in waist to hip ratio, obesity increased leading to worsening of PCOS features. ${ }^{10,11}$

When the individual components of the defining criteria for MBS were compared, waist circumference of $\geq 88 \mathrm{~cm}$ was seen in $71 \%$ cases of MBS compared to cases without MBS $(10.1 \%)$ in our study. This was consistent with the findings of Indu et al who observed $100 \%$ cases and Zahiri et al with $95.2 \%$ cases. ${ }^{8,12}$ Thereby, suggesting strong association between intra-abdominal fat distribution, central adiposity and metabolic syndrome in women with PCOS.

High density lipoprotein (HDL) cholesterol level cut off was taken as $<50 \mathrm{mg} / \mathrm{dl}$ seen in most $(80.6 \%)$ cases in the MBS category in the current study. Indu et al and Zahiri et al also observed this trend in their studies with MBS group, $84.8 \%$ and $98.4 \%$, respectively. HDL have a protective role in metabolic diseases, therefore reduced levels of HDL can be an independent factor in development of MBS. Subjects with triglyceride level of $\geq 150 \mathrm{mg} / \mathrm{dl}$ in the MBS group (96.8\%) were comparable to the study of Indu et al $(100 \%)$ and Zahiri et al $(88.7 \%)$. This indicated a direct association of increased triglyceride levels with metabolic syndrome and PCOS. ${ }^{8,12}$
Hypertension ( $\mathrm{BP} \geq 130 / 85 \mathrm{mmHg}$ ) as a component of MBS, was observed in $25.8 \%$ cases in subjects with MBS group in our study which was similar to the findings of Zahiri et al (27.4\%). However, Indu et al in their study observed all cases of MBS $(100 \%)$ had hypertension. ${ }^{8,12}$

Fasting blood sugar levels were an important component of MBS defining criteria and also predicting type 2 diabetes mellitus in subjects. Indu et al observed that most $(87.8 \%)$ cases of MBS had an FBS $\geq 110 \mathrm{mg} / \mathrm{dl} .{ }^{8}$ In the current study, more than half of the MBS subjects (64.5\%) had this component. However, in another similar study by Zahiri et al, the results showed only $19.4 \%$ MBS cases having FBS $\geq 110 \mathrm{mg} / \mathrm{dl}$. ${ }^{12}$ It may be noted that the latter study was a study conducted in the middle-east compared to the other two former studies performed in the Indian sub-continent, the difference in dietary habits and food preferences may have influenced their result.

PCOS was known to be affected by presence of obesity and its degree. As obesity exacerbated, metabolic and reproductive abnormalities also increased in women with PCOS. While comparing the clinical profile of lean and obese in PCOS, there was no significant statistical association, which was also concluded by Akshaya et al in their study. ${ }^{9}$ However, on studying the pattern of clinical features, it may be noted that clinical features seen in PCOS were more pronounced in obese group.

After comparison with various different studies, we concluded that our findings and observations were comparable to almost all parallel studies performed in different racial, ethnic and geographical backgrounds. This indicated that occurrence of MBS in women with PCOS was more frequent and majority of influences involved were universal.

A large multicentric study needed to be done for more elaborate evaluation of the relationship between MBS and PCOS.

\section{CONCLUSION}

From the present study, it can be concluded that PCOS is a well-known gynecological endocrinal disorder, which has been associated with metabolic disturbances leading to the development of metabolic syndrome. MBS in this study was found to be associated in women of higher age groups, urban residence, non-vegetarian diet, education, a high socio-economic status and obesity. While obesity alone is not considered the provoking event in the development of the PCOS, it can worsen associated reproductive and metabolic functions. Individual components of MBS can be used to predict MBS in women with PCOS. The data collection and observations of the study were made by a single observer, thereby eliminating inter-observer bias. Subjects were chosen irrespective of race, ethnicity and geographical location, which makes our results more relatable to the general population. A single standard criterion for the diagnosis of PCOS (Rotterdam 
criteria) and MBS (NCEP ATP III) throughout the study was used, maintaining uniformity and pertinency of our observations.

\section{Funding: No funding sources}

Conflict of interest: None declared

Ethical approval: The study was approved by the Institutional Ethics Committee

\section{REFERENCES}

1. Stein IF. Amenorrhea associated with bilateral polycystic ovaries. Am J Obstet Gynecol. 1935;29(2):181-91.

2. Ehrmann DA. Polycystic ovary syndrome. N Engl J Med. 2005;352(12):1223-36.

3. Franks S. Polycystic ovary syndrome. N Engl J Med. 1995;333(13):853-61.

4. Rotterdam ESHRE/ASRM-Sponsored PCOS Consensus Workshop Group. Revised 2003 consensus on diagnostic criteria and long-term health risks related to polycystic ovary syndrome (PCOS). Human Reprod. 2004;19(1):41-7.

5. National Cholesterol Education Program (US). Expert panel on detection, treatment of high blood cholesterol in adults. Third report of the National cholesterol education program (NCEP) expert panel on detection, evaluation, and treatment of high blood cholesterol in adults (adult treatment panel III). Circulation. 2002;106(25):3143-421.

6. Carmina E, Rosato F, Janni A, Rizzo M, Longo RA. Relative prevalence of different androgen excess disorders in 950 women referred because of clinical hyperandrogenism. Int $\mathbf{J}$ Clin Endocrinol Metab. 2006;91(1):2-6.

7. Dey R, Mukherjee S, Roybiswas R, Mukhopadhyay A, Biswas SC. Association of metabolic syndrome in polycystic ovarian syndrome: an observational study. J Obstet Gynaecol India. 2011;61(2):176-81.

8. Indu NR, Hiremath PB, Sanyal U, Hiremath R. Prevalence of metabolic syndrome in women with polycystic ovarian syndrome: an observational study in a tertiary care centre in Pondicherry, India. Int J Reprod Contracept Obstet Gynecol. 2018;7(9):377480.

9. Akshaya S, Bhattacharya R. Comparative study of clinical profile of lean and obese polycystic ovary syndrome women. Int J Fertil Steril. 2016;5(8):25304.

10. Ehrmann DA, Liljenquist DR, Kasza K, Azziz R, Legro RS, Ghazzi MN. PCOS/Troglitazone Study Group. Prevalence and predictors of the metabolic syndrome in women with polycystic ovary syndrome. Int J Clin Endocrinol Metab. 2006;91(1):48-53.

11. Mandrelle K, Kamath MS, Bondu DJ, Chandy A, Aleyamma TK, George K. Prevalence of metabolic syndrome in women with polycystic ovary syndrome attending an infertility clinic in a tertiary care hospital in south India. J Hum Reprod Sci. 2012;5(1):26.

12. Zahiri Z, Sharami SH, Milani F, Mohammadi F, Kazemnejad E, Ebrahimi H, et al. Metabolic syndrome in patients with polycystic ovary syndrome in Iran. Int J Fertil Steril. 2016;9(4):490.

Cite this article as: Gupta J, Minhas S, Jindal M. A prospective study of predictors of metabolic syndrome in women with polycystic ovary syndrome. Int J Reprod Contracept Obstet Gynecol 2022;11:775-80. 